\title{
miR-19b promotes tumor growth and metastasis via targeting TP53
}

\author{
YU FAN, ${ }^{1}$ SHENYI YIN, ${ }^{1}$ YANG HAO, ${ }^{1}$ JUNYU YANG, ${ }^{1}$ HANSHUO ZHANG, ${ }^{1}$ CHANGHONG SUN, ${ }^{1}$ MING MA, \\ QING CHANG, ${ }^{1,3}$ and JIANZHONG JEFF $\mathrm{XI}^{1,2,3}$ \\ ${ }^{1}$ Biomedical Engineering Department, College of Engineering, ${ }^{2}$ State Key Laboratory of Biomembrane and Membrane Biotechnology, Institute \\ of Molecular Medicine, Peking University, Beijing, 100871, China
}

\begin{abstract}
Tumor suppressor TP53 (or p53) is one of the most important regulators in numerous physiological and pathological processes. Recently, the miRNA-mediated post-transcription regulation of p53 has been studied. However, systematic studies of miRNA targeting sites within the $p 53$ gene are still a challenging task. Here, we developed a dual-color assay capable of identifying miRNA targeting sites in a certain gene, specifically p53, in a simple, direct, and robust manner. Results showed that p53 was a direct and critical target of miR-19b, but not miR-19a, regardless of sequence similarity. Overexpression of miR-19b observed in human cancer cells can diminish p53 protein levels and, subsequently, downstream components such as Bax and p21. This miR-19b-mediated p53 reduction was shown to promote cell cycle, cell migration or invasion, and repress senescence and apoptosis in vitro. Further investigation revealed that miR-19b controls tumor growth and metastasis in vivo. Therefore, it is possible that miR-19b antagomirs or sponges could be developed as therapeutic agents against tumor development.
\end{abstract}

Keywords: miRNA; TP53; tumor metastasis

\section{INTRODUCTION}

The tumor suppressor $p 53$ is especially important to numerous cellular processes. Under normal conditions, the p53 protein is maintained in an inactive state through low expression level and constant degradation. Responding to various cellular stresses, such as hypoxia, oncogene activation, or DNA damages, p53 is activated as a crucial modulator of DNA repair, transcription, cell cycle arrest, apoptosis, autophagy, and tumor development (Chao et al. 2006; Tasdemir et al. 2008; Meylan et al. 2009). p53 accomplishes its functions via regulation of many downstream targets such as p21, Bax, Puma, and Bcl-2 (Smith et al. 2000; Thomas et al. 2000; Galbiati et al. 2001; Chipuk et al. 2004; Liu et al. 2010). The $p 53$ gene is mutated or lost in over $50 \%$ of human cancers, which may cause irrepressible cell division and tumor formation (Levine et al. 1991; Bennett et al. 1999; Hamzehloie et al. 2012).

Although regulation of $p 53$ expression and activity has been extensively investigated (Murray-Zmijewski et al. 2008), a detailed mechanism still remains elusive. Recently, studies have indicated a complex regulatory circuit between

\footnotetext{
${ }^{3}$ Corresponding authors

E-mail bj_changqing@163.com

E-mail jzxi@pku.edu.cn

Article published online ahead of print. Article and publication date are at http://www.rnajournal.org/cgi/doi/10.1261/rna.043026.113.
}

p53 and microRNAs (miRNAs), including miR-125b, miR504, miR-380, miR-15a, miR-16, miR-25, and miR-30d (Le et al. 2009; Hu et al. 2010; Li et al. 2010; Kumar et al. 2011). miRNAs are a class of small endogenous noncoding RNAs $\sim 22$ nt long. They regulate expression of targeted genes in a post-transcriptional manner, usually leading to mRNA degradation or translational repression (Bartel 2004). Unlike conventional mediators, one miRNA is estimated to regulate over 100 targeted genes.

Up to now, it has been a challenging task to identify all miRNAs targeting specific genes. Conventionally, identification of miRNA target genes relied on a luciferase assay. Although accurate and sensitive, the luciferase assay is expensive and labor intensive, and thus not suitable for the largescale investigation. On the other hand, the fluorescent image-based assays are low cost, but have low sensitivity and high false-positive signals. To address these limitations, we developed a new dual-signal screen assay suitable for the identification of miRNA targeting sites in a certain gene. Using a library of 236 miRNAs, we demonstrate that our new dual-color assay is capable of identifying miRNA target sites on p53 in a simple, direct, robust, cost- and labor-effective

(c) 2014 Fan et al. This article is distributed exclusively by the RNA Society for the first 12 months after the full-issue publication date (see http:// rnajournal.cshlp.org/site/misc/terms.xhtml). After 12 months, it is available under a Creative Commons License (Attribution-NonCommercial 4.0 International), as described at http://creativecommons.org/licenses/by-nc/4.0/. 
manner. Results of this study will enable faster identification and a more precise understanding of the underlying tumorigenic molecular pathways involving p53, as well as facilitate the development of custom preventative and/or therapeutic strategies for p53-based cancers.

\section{RESULTS}

\section{Large-scale dual-color assay screening} and identification of miR-19b directly targeting p53

In brief, a couple of vectors, referred to as miRNA-red-fluorescent protein (miR-RFP) and Reporter-p53, were constructed (Fig. 1A). miR-RFP expressed an 200-300-bp pri-miRNA as an intron driven by the promoter of EF1 $\alpha$, as well as RFP-Puro protein, while Reporter-p53 contained a human $p 533^{\prime}$ UTR cDNA sequence downstream from d2eGFP cDNA. In comparison to conventional screening assays, our dual-color method has two unique features: (1) high sensitivity due to the use of d2eGFP, and (2) high accuracy resulting from evaluation of silencing based on the ratio of two color signals (green/red), which minimizes the noise from transfection and culture variation among wells in a multiple-well plate.

Using this method, we screened miRNA targeting sites along the p53 $3^{\prime}$ UTR within a library of $\sim 236$ pri-miRNAs (Fig. 1B; Supplemental Table 1). We successfully found five miRNAs that reduced the relative luminance, including miR-30d and miR-125b that previously reported to target $p 533^{\prime}$ UTR (Supplemental Table 2). Among these candidate miRNAs, miR-19b showed the most reduction capacity, that is, suppressing the reporter signal by $\sim 70 \%$ in Hela cells (Fig. 1C). To further validate this result, a luciferase assay was performed by constructing a group of luciferase reporters, each containing the wildtype $p 533^{\prime}$ UTR sequence or mutant sites (Fig. 1D). Luciferase activity was found to be reduced by $\sim 40 \%$ when miR- $19 \mathrm{~b}$ was cotransfected with the wild-type reporter, whereas the activity was not altered when miR-19b was cotransfected with the mutant reporter. Given that the firefly luciferase gene contains a cryptic promoter that may influence its transcription result (Vopalensky et al. 2008), we examined the mRNA level of lucifWhitney test. erase gene by quantitative real-time PCR (qRT-PCR) and confirmed that miR-19b affected its translation but not its transcription (Supplemental Fig. S1A). Furthermore, we changed the reporter gene by Renilla luciferase that did not have the cryptic promoter, and observed the same result by luciferase assay (Supplemental Fig. S1B). Together, these data demonstrated that miR-19b directly targets p53 on its $3^{\prime}$ UTR and represses its translation.

It should be noted that miR-19a belongs to the same miRNA family as miR-19b with only a single differing nucleotide at the position of 11 . Both miRNAs have an identical "seed region" and are perfectly matched between the p53 3' UTR sequence and the "seed region" at nucleotides 2-9 (Fig. 1E). However, no significant change in dual-color assay was observed when miR-19a was cotransfected with the wildtype reporter (Supplemental Fig. S1C). This finding was confirmed using the luciferase assay (Fig. 1F). Thus, these results showed that $p 53$ is a direct and critical target regulated by miR-19b, but not miR-19a.

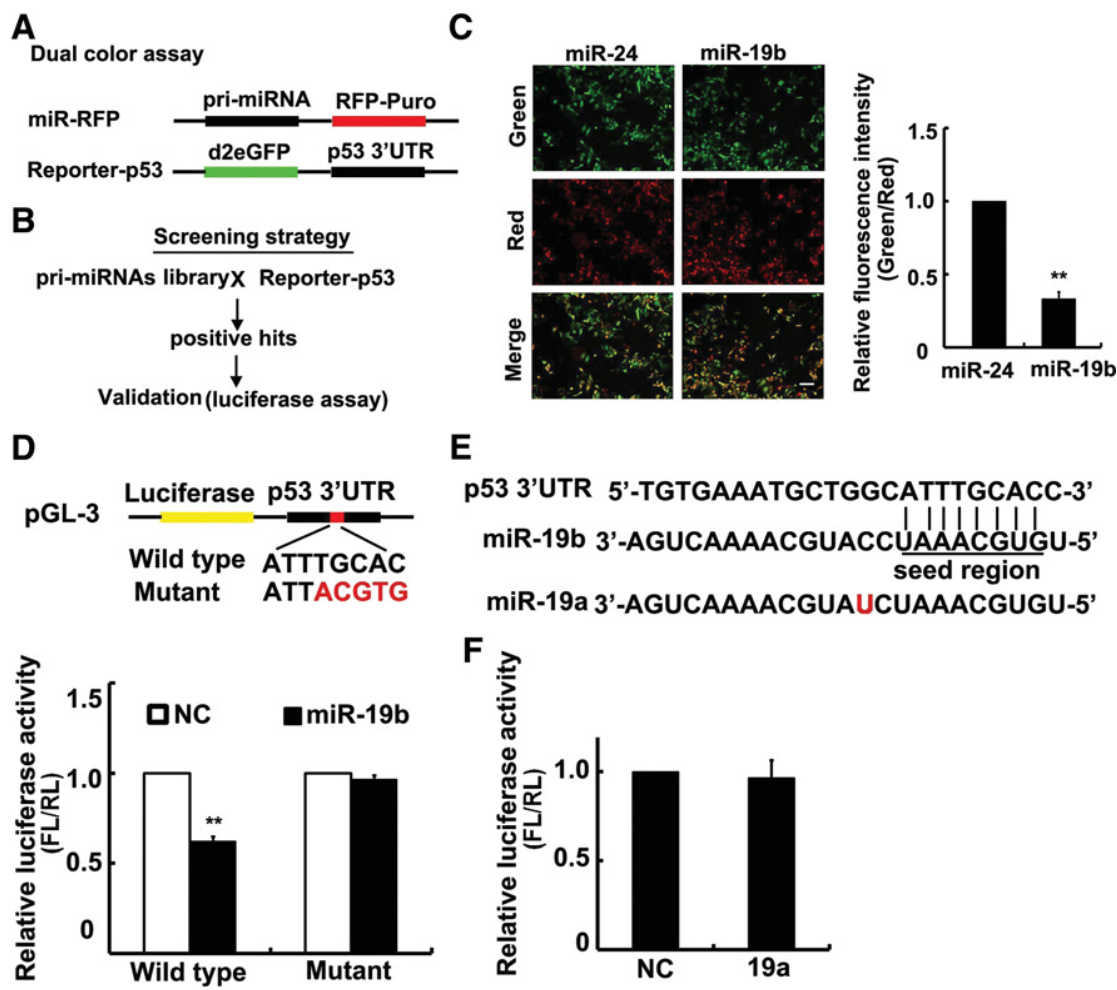

FIGURE 1. miRNA-19b directly targets $p 53$. $(A, B)$ Diagram of plasmids design $(A)$ and screening strategy $(B)$. $(C)$ Partial result of dual-color screening. Overexpression of miR-19b sufficiently decreased d2eGFP production, whereas miR-24 had no significant effect. Quantitative data of the relative RUE is shown on the right. Scale bar, $20 \mu \mathrm{m}$. (D) Validation of screening results by luciferase assay. The diagram shows the wild-type $p 533^{\prime}$ UTR and the different nucleotides in the mutant plasmid. Luciferase assay results are shown below. miR-19b repressed luciferase activity with the wild-type $p 533^{\prime}$ UTR in Hela cells, but not the mutant UTR. (E) Sequence comparison of miR-19b and miR-19a. The red character denotes a single differing nucleotide. $(F)$ Luciferase assay for $p 533^{\prime}$ UTR in Hela cells transfected with miR-19a. miR-19a did not affect luciferase activity via $p 533^{\prime}$ UTR. (FL) Firefly luciferase; (RL) Renilla luciferase. All histograms are presented as mean values \pm SEM from five independent experiments. Data are tested by a Mann- 
miR-19b down-regulates endogenous $\mathrm{p} 53$ protein and its downstream mediators in human cells

To investigate whether miR-19b can regulate endogenous p53 expression, miR-19b was transfected into Hela cells and p53 levels of both transcriptional and translational were examined after $48 \mathrm{~h}$. Western blot and qRT-PCR showed that p53 protein levels decreased by $50 \%$, while mRNA levels were not altered (Fig. 2A,B). Similarly, the decrease of endogenous $\mathrm{p} 53$ protein was observed in both MCF7 and Huh7 cell lines when miR-19b was overexpressed, while mRNA level remained unchanged (Fig. 2A,B). These results indicated that miR-19b regulates endogenous p53 in a post-transcriptional manner.

Next, we studied whether miR-19a could alter the levels of endogenous p53 in Hela, MCF7 or Huh7 cells, since the expression levels of miR-19a is similar to miR-19b in those cells (Supplemental Fig. S2A). Western blot showed that the overexpression of miR-19a could not alter the levels of endogenous p53 in Hela, MCF7 or Huh7 cells (Fig. 2A).

Then it was determined whether miR19b-mediated p53 reduction can also affect the expression of endogenous p53 downstream components, such as Bax and $\mathrm{p} 21$. We first excluded the possibility that either Bax or p21 was targeted by miR-19b on the basis of luciferase assay (Supplemental Fig. S2B). The expression levels of both Bax and p21 was decreased when miR-19b was overexpressed in three cell lines (Fig. 2A). Consistently, no change of Bax or p21 was observed when miR-19a was overexpressed (Fig. 2A).

In contrast, the sponge of miR-19b resulted in the silencing of miR-19b, thus increasing p53 and its downstream components, such as Bax or p21, in both Hela and MCF7 cells (Fig. 2C,D). Furthermore, we did the experiments of p53 rescue, in which p53 expression is restored by exogenous $p 53$ cDNA (without $p 53$ $3^{\prime}$ UTR) transfection in miR-19b overexpressing cells (Fig. 2C). Clearly, the expression of p53 and its downstream components increased compared with ones in cells only overexpressing miR19b (Fig. 2D). Together, these data suggest that miR-19b is able to directly suppress 553 expression, thereby regulating downstream components of the p53 regulatory pathway.
miR-19b-mediated $p 53$ regulation influences the cell cycle, migration, invasion, senescence, and apoptosis

p53 has been shown to regulate numerous cellular activities, such as cell cycle, cellular development, migration, invasion, senescence, and apoptosis (Hollstein et al. 1991). We investigated whether miR-19b-mediated p53 repression affects these cellular processes. To show the rescue capability, we transfected with the proper concentration of the pcDNAp53 plasmid into cells, otherwise strong overexpression of p53 would cause serious cell apoptosis. First, the effect of miR-19b on cell proliferation was characterized. The overexpression of miR-19b resulted in greater proliferation rate in
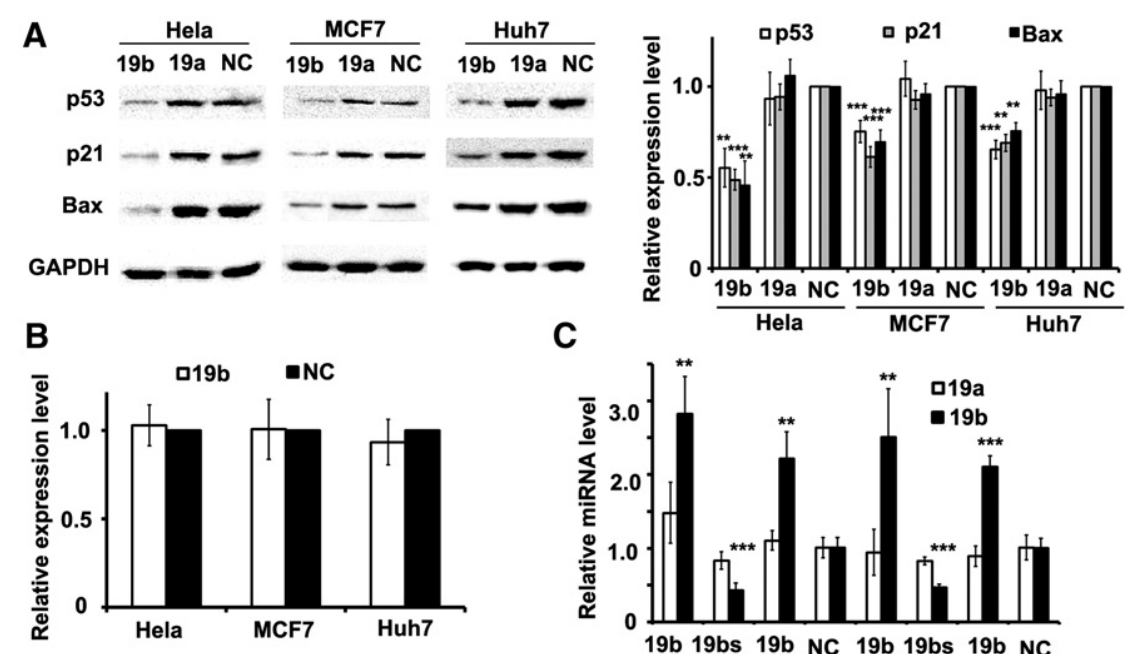

c

D
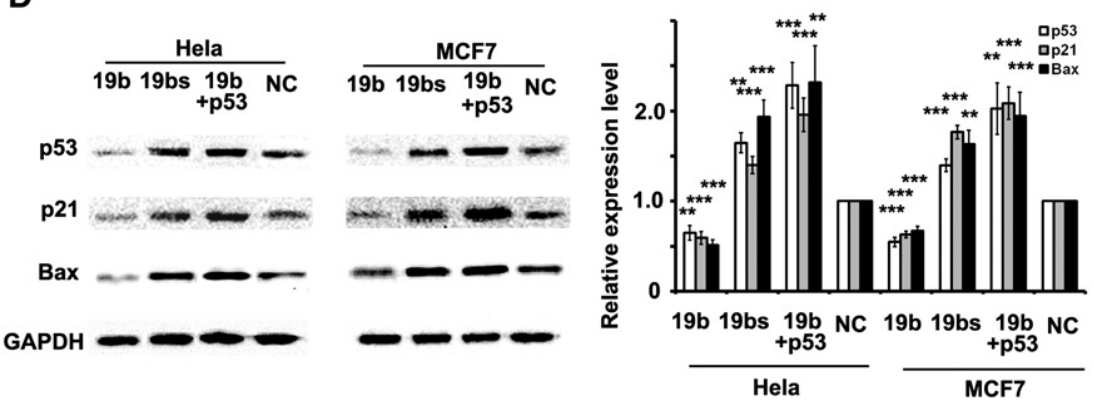

FIGURE 2. miR-19b represses endogenous p53 and its downstream components. (A) Western blot of p53, p21, and Bax protein in different cells. Due to overexpression of miR-19b, generation of endogenous p53 and its downstream proteins were significantly inhibited in all three cell types, while miR-19a did not alter the expression level of any proteins. Corresponding protein levels were quantified and shown at right. (B) The mRNA level of p53 in Hela, MCF7, and Huh7 cells transfected with miR-19b or negative control (NC) as examined by qRT-PCR. No significant difference was observed between the two groups in all cell types. $(C)$ The expression level of miR-19a and miR-19b examined by qRT-PCR in Hela and MCF7 cells transfected with miR-19b, miR-19b sponge (19bs), and $p 53$ cDNA together with miR-19b and miR-NC. (D) Western blot of p53, p21, and Bax in cells described in C. p53 protein level was decreased by overexpression of miR-19b, but increased when miR-19b was blocked by the sponge. The level of $\mathrm{p} 21$ and Bax changed along with p53. Corresponding protein levels were quantified and shown at right. Data in $A$ and $B$ are tested by a Mann-Whitney test, and in $C$ and $D$ are tested by an ANOVA test and further verified by a Bonferroni post-test. All histograms are presented as mean values \pm SEM derived from five independent experiments. 
both Hela cells and MCF7 cells, whereas the increase of the proliferation rate could be reversed when p53 was overexpressed simultaneously (Fig. 3A). The silencing of miR-19b resulted in a lesser proliferation rate (Fig. 3A). Upon comparison of the apoptosis rate among the three cell types, the inverse pattern was found (Fig. 3B). Further investigation of miR-19b's effect on cell cycle arrest revealed that overexpression of exogenous miR-19b caused exiting from the $G_{1}$ phase and entry into $S$ or $\mathrm{G}_{2} / \mathrm{M}$ phase in both Hela and MCF7 cells (Fig. 3C).

Next, transwell assay was used to investigate the effect of miR-19b on cell motility. The overexpression of miR-19b led to a higher migration and invasion rate in both Hela cells and MCF7 cells, whereas the increase of migration and invasion rate could be reversed when p53 was overexpressed simultaneously (Fig. 3D,E). The silencing of miR-19b resulted in lesser migration and invasion rate (Fig. 3D,E). $\beta$-galactosidase staining showed that cellular senescence was reduced when miR-19b was overexpressed in both Hela cells and MCF7 cells, but increased 50\% when miR-19b was silenced or p53 was overexpressed simultaneously (Fig. 3F). These results indicated that miR-19b is capable of promoting motility and preventing cellular senescence and death, indicating that miR-19b functions as an oncogene.

\section{miR-19b promotes tumor growth and metastasis in vivo}

We then investigated the impact of miR$19 \mathrm{~b}$-mediated regulation of p53 in vivo. We constructed a group of lentiviral vectors expressing miR-NC, pri-miR-19b, or miR-19b sponge, and then generated a group of stable Hela cell lines, referred to as Hela-NC, Hela-19b, or Hela-sp, in which the expression level of miR-19b was either enhanced or decreased, respectively (Fig. 4A). Results confirmed that p53 expression was inhibited in Hela$19 \mathrm{~b}$ cells and increased in Hela-sp cells (Fig. 4B). Hela-NC, Hela-19b, and Helasp cell lines were subcutaneously implanted into nude mice. At $8 \mathrm{wk}$, mice were killed, and the tumors were measured by weight. A significant decrease was observed in the Hela-sp-implanted group, whereas the tumors of the Hela$19 \mathrm{~b}$ group were heavier than those in the other two groups (Fig. 4C). Moreover, tumors derived from the Hela-sp cells were well encapsulated and noninvasive (Fig. 4D), indicating miR-19b silencing could restrict tumor cell invasion.

Immunohistochemical analyses of the lungs revealed that metastatic nodules had developed in the mice injected with Hela-19b cells, but not in mice implanted with Hela-sp cells

(Fig. 4E). Together, these results indicate that suppression of
A

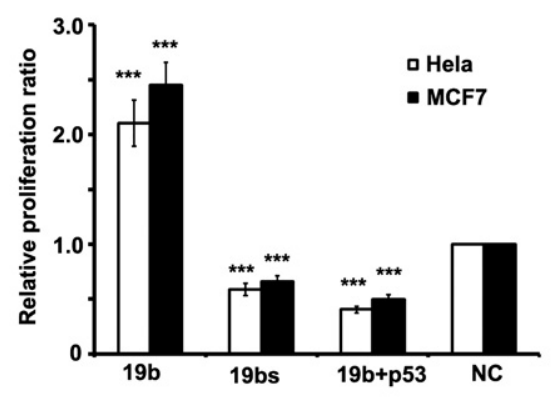

C

\begin{tabular}{|c|c|c|c|}
\hline Cell & Phase & $m i R-19 b$ & miR-NC \\
\hline \multirow{3}{*}{ Hela } & G1 & $58.7 \pm 2.4^{\star \star \star}$ & $70.3 \pm 1.1$ \\
\hline & s & $20.0 \pm 0.8$ & $17.4 \pm 1.4$ \\
\hline & G2 & $21.1 \pm 2.5$ & $12.4 \pm 0.7$ \\
\hline \multirow{3}{*}{ MCF7 } & G1 & $52.8 \pm 1.5^{*}$ & $60.9 \pm 1.6$ \\
\hline & s & $27.4 \pm 0.7$ & $24.0 \pm 0.7$ \\
\hline & G2 & $18.9 \pm 2.4$ & $14.4 \pm 1.6$ \\
\hline
\end{tabular}

E

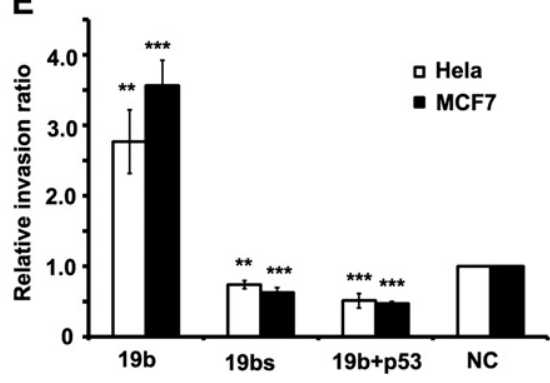

B

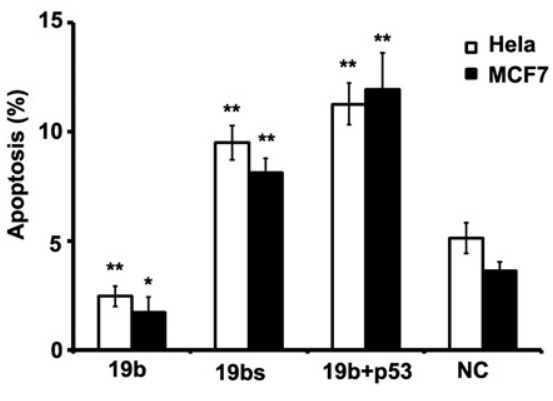

D

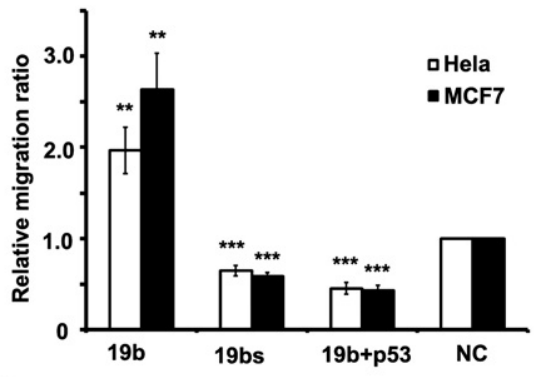

$\mathbf{F}$

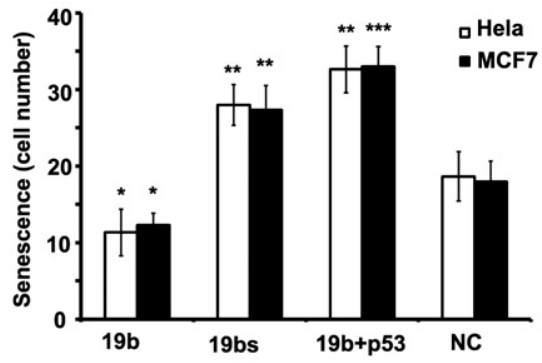

FIGURE 3. miR-19b promotes the cell cycle, cell migration, and invasion, while inhibiting senescence and apoptosis. (A) The proliferation rate of cells as detected by EdU staining. Both Hela and MCF7 cells transfected with miR-19b divided faster than control cells, while proliferation was retarded in the sponge-transfected cells. (B) The apoptotic rate of cells was measured by Annexin$\mathrm{V}$ staining. The rate of apoptosis was lower in cells transfected by miR-19b relative to the other cell types. $(C)$ The cell cycle was detected by flow cytometry with propidium iodide (PI) staining in Hela or MCF7 cells. More cells entered $\mathrm{G}_{2} / \mathrm{M}$ phase after introducing miR-19b. Data are tested by Mann-Whitney test. $(D, E)$ Migration $(D)$ and invasion $(E)$ rates detected by transwell assay showed that $19 \mathrm{~b}$-overexpressed cells had approximately threefold greater migration and invasion potency than NC cells, while migration and invasion rates of cells transfected with the miR-19b sponge were half as potent as NC cells. $(F)$ Senescence rates were detected by $\beta$-galactosidase staining and the number of $\beta$-gal ${ }^{+}$cells per microscope field were calculated. Overexpression of miR-19b reduced the rate of senescence, while miR-19b sponge drove a higher rate of senescence. In $A, B, D, E$, and $F$, all of the cell phenotypes attributed to miR-19b could be rescued by cotransfecting plasmids expressing p53 cDNA without $3^{\prime}$ UTR. All histograms are presented as mean \pm SEM from at least three independent experiments. Data, except for $C$, are tested by ANOVA test and further verified by Bonferroni post-test. 

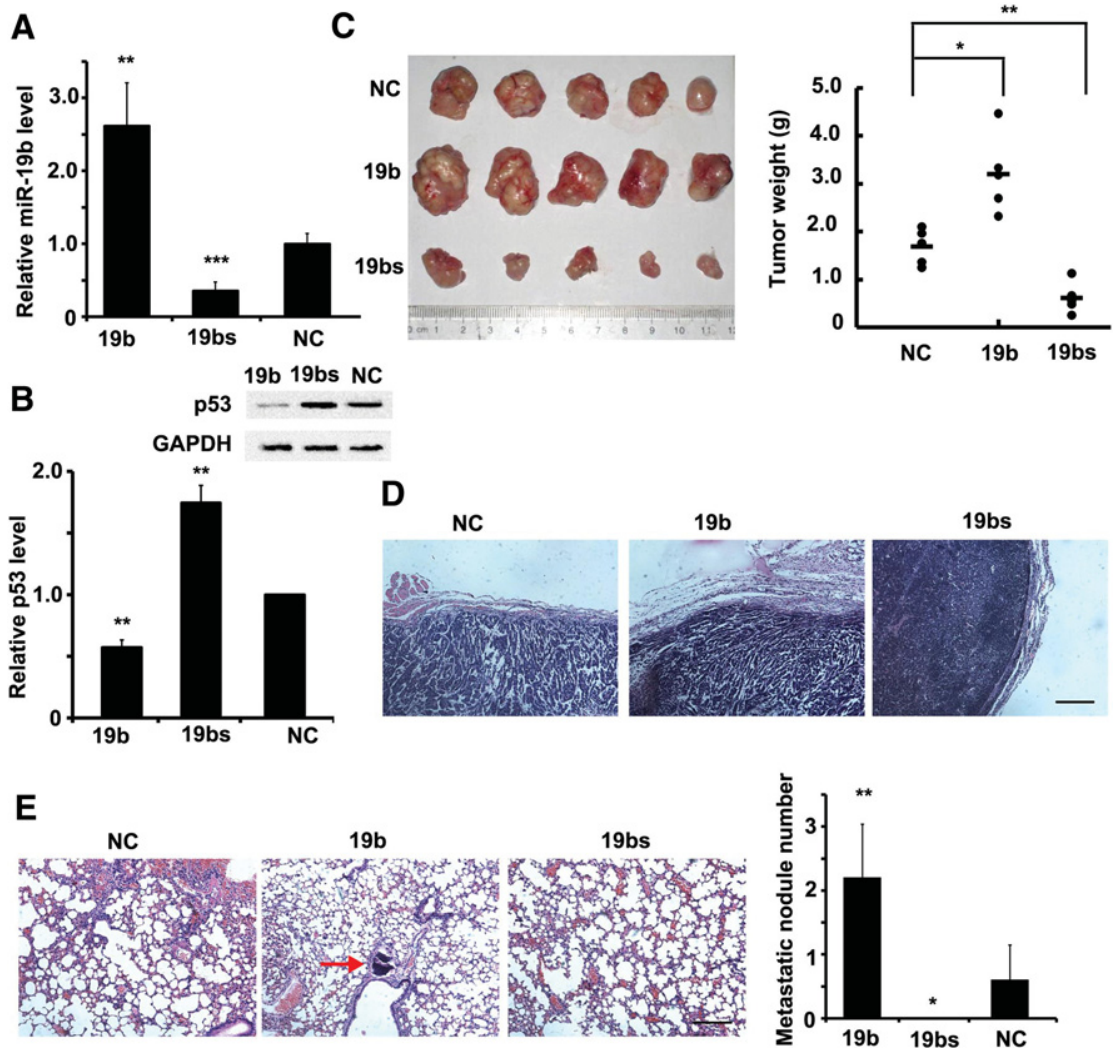

FIGURE 4. miR-19b regulates tumor growth and metastasis in vivo. $(A, B)$ miR-19b levels $(A)$ and $\mathrm{p} 53$ protein levels $(B)$ were measured by qRT-PCR or Western blot, respectively, in three stable cell lines: Hela-19b (19b), Hela-sp (19bs), and Hela-NC (NC). (C) Three cell types were subcutaneously implanted into nude mice. $n=5$. After $8 \mathrm{wk}$, mice were killed and the tumors were measured. Tumors formed by Hela-19b were the largest in size and weight, while tumors from Hela-sp cells were much smaller. $(D)$ Haematoxylin and eosin (H\&E) staining of the tumor edge. Hela-sp tumors showed a clear edge and were noninvasive. Scale bar, $50 \mu \mathrm{m}$. (E) H\&E staining of mouse lungs, and the metastatic nodule numbers in each lung were calculated. The red arrow indicates the metastatic nodule. They were found in all of the five mice implanted with Hela$19 \mathrm{~b}$ cells, few in those implanted with Hela-NC cells, but none in Hela-sp cells. Scale bar, $50 \mu \mathrm{m}$. All histograms are presented as mean \pm SEM from five independent experiments. Data are tested by an ANOVA test and further verified by Bonferroni post-test.

miR-19b inhibits both tumor growth and metastasis in vivo, consistent with in vitro proliferation and migration assays above.

\section{DISCUSSION}

In this study, we developed a novel approach to large-scale identification of miRNA-targeting sites in specific genes in a simple, direct, and robust manner. We identified five candidate miRNAs targeting p53 with the exception of miR-380, one of the known ones. Other known miRNAs targeting p53 were not included in the screening library. We demonstrated that miR-19b directly targets $p 53$ by base-pairing to its $3^{\prime}$ UTR. In addition, it was found that the miR-19b-mediated p53 repression promoted cellular proliferation, accelerated migration and invasion, and prevented senescence and apoptosis. Therefore, it is possible that miR-19b inhibitors, such as antagomirs or sponges can be used as therapeutic agents against tumorigenesis.

As a member of the miR-17-92 cluster, miR-19b has been shown to play a role as an oncogene in multiple tissues. For instance, through suppressing vasopressin-activated calcium-mobilizing receptor-1 (CUL5), miR-19b contributes to human cervical carcinoma cellular proliferation and invasion (Xu et al. 2012). Our results indicated a direct relation between miR-19b and $p 53$, one of the most well-studied transcription factors and tumor suppressors. Since the p53 signaling pathway can be stimulated by a plethora of environmental factors and further induces multiple cellular responses in various tissues, the influence of miR-19b on tumorigenesis and other biological processes is global and crucial.

miR-19b is noted to be conserved in vertebrates, but the miR-19b targeting site within the $p 533^{\prime}$ UTR can only be predicted in primates. Nevertheless, miR-19b also participated in mouse carcinogenesis by repressing other tumor suppressors, such as PTEN, and activating the Akt-mTOR pathway (Olive et al. 2009). This phenomenon indicates that a miRNA conserved function may rely on targeting different proteins.

Interestingly, the expression of miR$19 \mathrm{~b}$ seems to be regulated by the $\mathrm{p} 53$ protein. For example, p53 interacts with the promoter of miR-17-92 and represses expression of the whole cluster, thus inducing apoptosis of the cell (Yan et al. 2009). Although regulation of miR-19b by $\mathrm{p} 53$ is only recognized in hypoxic conditions, this kind of feedback regulation may exist in response to other environment stimuli. Thus, these results imply a more complicated regulatory pathway in which miRNAs are involved.

Finally, our experiments showed that miR-19a does not target $p 53$, even if it shares high-sequence similarity with miR19b. It is well known that a perfect match between the target sequence and a "seed region" at nucleotides $2-8$ is critically important for the target predication. Actually, both miR-19a and miR-19b share a number of targeted genes, such as ATXN1, CUL5, and TLR2 (Lee et al. 2008; Philippe et al. 2012; Xu et al. 2012). However, miR-19a, but not miR-19b, was found to target TNF- $\alpha$ (Liu et al. 2010), whereas mainly miR-19b was involved in the NF- $\mathrm{kB}$ pathway by targeting RNF11 (Gantier et al. 2012). We constructed their $3^{\prime}$ UTR into pGL3 vectors and cotransfected them with miR-19a or miR-19b, respectively. Luciferase assay showed that both 
miR-19a and miR-19b repressed the relative luciferase activity in all five genes, but showed a significant difference of repression to CUL5, RNF11, and TNF- $\alpha$ (Supplemental Fig. S3). Taking this into account, these results indicate that beyond high complementation in the "seed region," miRNAs can also recognize their target sequence by other mechanisms that are presently unknown. Clearly, an accurate and highthroughput method for the identification of all miRNA-regulated target genes would ultimately help unveil the network of interactions between miRNA and target genes.

\section{MATERIALS AND METHODS}

\section{Cell culture, transfection, and lentivirus package}

Hela, Huh7, 293T, and MCF7 cells were cultured in high-glucose Dulbecco's Modified Eagle Medium (DMEM) containing 10\% fetal bovine serum (FBS), 100 units $/ \mathrm{mL}$ penicillin and $0.1 \mathrm{mg} / \mathrm{mL}$ streptomycin. All of the cells were cultured under humidified conditions in $5 \% \mathrm{CO}_{2}$ at $37^{\circ} \mathrm{C}$. Cells were washed with $\mathrm{PBS}$ and incubated in $0.25 \%$ trypsin containing $5 \mathrm{mM}$ EDTA every $2-3 \mathrm{~d}$. DMEM containing $10 \%$ FBS were added to terminate trypsin. After centrifugation, cells were diluted by the medium, counted via haemocytometer, and then planted with appropriate concentration.

Plasmids were transfected using Lipofectamine 2000 (Invitrogen). The cell number and plasmid amount followed the manufacturer's protocol.

Lentivirus was packaged in $293 \mathrm{~T}$ cells, and Hela cells were infected with a different virus as indicated. Culture medium was changed $48 \mathrm{~h}$ after infection.

\section{Large-scale screening of miRNA targeting p53}

We carried out the large-scale screening of miRNA targeting $p 53$ by use of the reverse-transfection method. Briefly, $1 \mu \mathrm{L}$ miR-RFP plasmids (200 ng) each containing a pri-miRNA as well as RFPPuro protein were mixed with $3 \mu \mathrm{L}$ OPTI-MEM (Invitrogen) and Lipofectamine 2000 (Invitrogen) and then mixed with $7.25 \mu \mathrm{L}$ $0.2 \%(\mathrm{w} / \mathrm{v})$ gelatin (Sigma, Type B) solution and printed on a well of 96-well culture dishes.

Hela cells were infected with lentivirus containing the GFP gene with a $p 53$ wild-type $3^{\prime}$ UTR. After being sorted by flow cytometry, the GFP-positive cells were cultured in the 96-well plate with normal culture condition. Forty-eight hours later, the fluorescence signal was examined.

We used a microscope system (Image Xpress, Molecular Devices) to automatically capture four images for each well and quantify the fluorescence intensity. The total green fluorescence intensity indicated UTR expression and the total red fluorescence intensity indicated exogenous miRNA expression. Consequently, we concluded a formula to calculate the Relative UTR Expression (RUE). RUE $=I_{\text {green }} / I_{\text {red }}$, where $I_{\text {green }}$ is the total green fluorescence intensity and $I_{\text {red }}$ is the total red fluorescence intensity. Finally, the RUE treated with a certain miRNA was normalized to that treated with miR-NC vector, which contained a scrambled sequence as a negative control. Each miRNA was tested at least four times, and the fold change of RUE $<0.9$ and $P$ value $<0.05$ was considered significant.

\section{3' UTR reporter assay}

Prior to screening, we first established a stable cell line, Reporter-p53, which expressed a human $p 533^{\prime}$ UTR cDNA sequence downstream from $d 2 e G F P$ cDNA. A $d 2 e G F P$ gene was inserted into a pLKO.1 lentiviral vectors, and then the wild-type $3^{\prime}$ UTR of $p 53$ was cloned as the $3^{\prime}$ UTR of $d 2 e G F P$ (forward primer: $5^{\prime}$-CTTGTTCCCCACT GACAGCCTCCCACC-3'; reverse primer: 5'-CTCAGACACACA GGTGGCAGCAAAGTTTTA-3'). This vector was packaged into lentivirus in 293T cells, and then infected to Hela cells.

For luciferase assay, the wild-type or mutant $p 533^{\prime}$ UTR were cloned into pGL3 plasmids, located $3^{\prime}$ to the firefly luciferase gene. This plasmid was cotransfected with pGL3 Renilla luciferase plasmid and miRNA plasmids into Hela cells. After 48 h, cells were lysed and luciferase activities were measured using the Dual Luciferase Reporter Assay System (Promega).

\section{p53 cDNA clone, miRNA sponge}

Total RNA of Hela cells were extracted with Trizol reagent (Tiangen Biotech, Co. Ltd), and cDNA was then reverse transcribed. p53 cDNA was cloned with the primers of forward: $5^{\prime}$-CGGGATCCA TGGAGGAGCCGCAGTCAGATCCTAG-3', and reverse: 5'-CGG AATTCTCAGTCTGAGTCAGGCCCTTCT- $3^{\prime}$. The cDNA was cloned into pcDNA3.1 vectors.

miR-19b sponge was designed with six repeats of the sequence: 5'-TCAGTTTTGCAGAAGTTTGCACATATA-3'. Oligonucleotides were synthesized and constructed into either pcDNA3.1 vectors or pLKO.1 lentiviral vectors.

\section{Transwell assays}

For migration assays, cells were seeded into the upper chamber of a Transwell insert (pore size, $8 \mu \mathrm{m}$; Costar) in $100 \mu \mathrm{L}$ serum-free medium per well. Medium $(600 \mu \mathrm{L})$ containing $10 \%$ serum was placed in the lower chamber to function as a chemoattractant. Nonmigratory cells were removed from the upper chamber by scraping with a cotton bud. The cells remaining on the lower surface of the insert were fixed with $4 \%$ formaldehyde (Sigma) and stained by DAPI (Roche). For invasion assays, cells were seeded in a Matrigel (Bio$\mathrm{Rad}$ )-coated chamber and pre-incubated at $37^{\circ} \mathrm{C}$ for $30 \mathrm{~min}$.

\section{Cell proliferation, senescence, and apoptosis assays}

For these assays, cells were seeded in a 24 -well plate at a number of $0.5 \times 10^{5}$ per well. Proliferation rate was analyzed by Cell-Light EdU Apollo488 In Vitro Imaging Kit (Ribobio). Twenty-four hours after seeding, culture medium was changed by medium containing $50 \mu \mathrm{M}$ EdU; 2 h later, cells were washed with PBS and fixed with $4 \%$ formaldehyde. Apollo staining was then carried on for $30 \mathrm{~min}$ at room temperature, and cells were finally stained by Hoechst.

For senescence assay, Senescence $\beta$-Galactosidase Staining Kit (Beyotime) was used after $48 \mathrm{~h}$ of seeding. After being fixed by $4 \%$ formaldehyde, cells were stained at $37^{\circ} \mathrm{C}$ overnight, followed by staining with DAPI.

Apoptosis assays were conducted using Annexin V-FITC Kit (Biosea Biotechnology Co. Ltd). Apoptotic cells were identified by labeling with Annexin V. Cells were incubated with Annexin V solution for $30 \mathrm{~min}$ at room temperature, followed by DAPI solution 
for $10 \mathrm{~min}$. Cells undergoing an apoptotic process were stained by Annexin V. All of the fluorescent images were taken by a Nikon TE2000-E (CCD: Regita 2000R, Qimaging). For counting, cells were quantified as the number of cells found in 15 random microscope fields in three independent inserts, and the ratio of signal/cell number was calculated.

\section{Quantitative real-time PCR}

Quantitative real-time PCR (qRT-PCR) was processed by Real Master Mix (Tiangen Biotech, Co. Ltd) using a Bio-Rad Opticon2 Real-Time PCR Detector (Bio-Rad Laboratories). The primers are shown below.

Forward primer for $p 53$ RT-PCR: 5'-TCAACAAGATGTTTTGCC AACTG-3'

Reverse primer for p53 RT-PCR: 5'-ATGTGCTGTGACTGCTTGT AGATG-3'

Forward primer for GAPDH RT-PCR: 5'-TGCACCACCAACT GCTTAGC-3'

Reverse primer for GAPDH RT-PCR: $5^{\prime}$-GGCATGGACTGTGGT CATGAG-3'

For miRNA detection, primers and protocols were supplied with the Bulge-Loop miRNA qPCR Primer Set (Ribobio). According to the manufacturer's instruction, the kit we used is based on the $2^{-\triangle \triangle \mathrm{Ct}}$ method to test the relative amount of miR-19a and miR19b. After total RNA of cells of the experimental group was extracted, miR-19a, miR-19b, and U6 were measured by different groups of primers, respectively, by qRT-PCR. Then the amount of miR-19a and miR-19b relative to U6 was calculated, respectively. Finally, these ratios were further normalized by the corresponding miRNA ratios in the control group. We repeated the experiment three times.

\section{Immunoblotting}

In brief, total protein extracted from cell lines was resolved by SDSPAGE, and then transferred to a polyvinylidene difluoride membrane (Millipore Corporation). The membranes were probed with antibodies against p53, p21, Bax, or GAPDH (Cell Signaling Technologies). The images were obtained by Quantity One software (Bio-Rad) and quantified by ImageJ software.

\section{Animal model and in vivo tumorigenesis assay}

For in vivo tumorigenesis assay, $1 \times 10^{7}$ Hela-19b, Hela-sp, and Hela-NC cells were subcutaneously implanted into each naked mouse, respectively. There were five mice per group. After $8 \mathrm{wk}$, mice were killed, tumors were picked and weighed, and tumors together with lungs were fixed and prepared for section and immunohistostaining. All research involving animals complied with protocols approved by the Laboratory Animal Center, Peking University.

\section{Immunohistochemistry}

Immunohistochemistry was accomplished at the Chinese Academy of Medical Sciences. Briefly, tissue samples were fixed in $4 \%$ para- formaldehyde overnight at room temperature, washed with PBS, transfered to $70 \%$ ethanol, and then embedded in paraffin, sectioned, and stained with haematoxylin and eosin.

\section{Statistical analysis}

For statistical analysis, the method was mentioned in each figure legend, respectively. A $P$-value $<0.05$ was considered statistically significant. ( $\left.{ }^{*}\right) P<0.05$; (**) $P<0.01$; (**) $P<0.001$ in all figures. Error bars, mean \pm SEM of at least three independent experiments.

\section{SUPPLEMENTAL MATERIAL}

Supplemental material is available for this article.

\section{ACKNOWLEDGMENTS}

This work was supported by projects of MOST (Grant Nos. 2011CB809106, 2012AA020103) and NSFC (Grant Nos. 81030040, 31371443, 30600142). We thank the Center for Age-related Diseases (CAD), Peking University for its support.

Received October 15, 2013; accepted February 24, 2014.

\section{REFERENCES}

Bartel DP. 2004. MicroRNAs: genomics, biogenesis, mechanism, and function. Cell 116: 281-297.

Bennett WP, Hussain SP, Vahakangas KH, Khan MA, Shields PG, Harris CC. 1999. Molecular epidemiology of human cancer risk: gene-environment interactions and $p 53$ mutation spectrum in human lung cancer. J Pathol 187: 8-18.

Chao C, Herr D, Chun J, Xu Y. 2006. Ser18 and 23 phosphorylation is required for p53-dependent apoptosis and tumor suppression. EMBO J 25: 2615-2622.

Chipuk JE, Kuwana T, Bouchier-Hayes L, Droin NM, Newmeyer DD, Schuler M, Green DR. 2004. Direct activation of Bax by p 53 mediates mitochondrial membrane permeabilization and apoptosis. Science 303: $1010-1014$.

Galbiati F, Volonte D, Liu J, Capozza F, Frank PG, Zhu L, Pestell RG, Lisanti MP. 2001. Caveolin-1 expression negatively regulates cell cycle progression by inducing $\mathrm{G}_{0} / \mathrm{G}_{1}$ arrest via a $\mathrm{p} 53 / \mathrm{p} 21^{\mathrm{WAF} 1 / \mathrm{Cip} 1}$ dependent mechanism. Mol Biol Cell 12: 2229-2244.

Gantier MP, Stunden HJ, McCoy CE, Behlke MA, Wang D, KaparakisLiaskos M, Sarvestani ST, Yang YH, Xu D, Corr SC, et al. 2012. A miR-19 regulon that controls NF- $\mathrm{BB}$ signaling. Nucleic Acids Res 40: 8048-8058.

Hamzehloie T, Mojarrad M, Hasanzadeh Nazarabadi M, Shekouhi S. 2012. The role of tumor protein 53 mutations in common human cancers and targeting the murine double minute 2-p53 interaction for cancer therapy. Iran J Med Sci 37: 3-8.

Hollstein M, Sidransky D, Vogelstein B, Harris CC. 1991. p53 mutations in human cancers. Science 253: 49-53.

Hu W, Chan CS, Wu R, Zhang C, Sun Y, Song JS, Tang LH, Levine AJ, Feng Z. 2010. Negative regulation of tumor suppressor p53 by microRNA miR-504. Mol Cell 38: 689-699.

Kumar M, Lu Z, Takwi AA, Chen W, Callander NS, Ramos KS, Young KH, Li Y. 2011. Negative regulation of the tumor suppressor p53 gene by microRNAs. Oncogene 30: 843-853.

Le MT, Teh C, Shyh-Chang N, Xie H, Zhou B, Korzh V, Lodish HF, Lim B. 2009. MicroRNA-125b is a novel negative regulator of p53. Genes Dev 23: 862-876. 
Lee Y, Samaco RC, Gatchel JR, Thaller C, Orr HT, Zoghbi HY. 2008. miR-19, miR-101 and miR-130 co-regulate ATXN1 levels to potentially modulate SCA1 pathogenesis. Nature Neurosci 11: $1137-1139$.

Levine AJ, Momand J, Finlay CA. 1991. The p53 tumour suppressor gene. Nature 351: 453-456.

Li J, Donath S, Li Y, Qin D, Prabhakar BS, Li P. 2010. miR-30 regulates mitochondrial fission through targeting p53 and the dynamin-related protein-1 pathway. PLoS Genet 6: e1000795.

Liu D, Ou L, Clemenson GD Jr, Chao C, Lutske ME, Zambetti GP, Gage FH, Xu Y. 2010. Puma is required for p53-induced depletion of adult stem cells. Nat Cell Biol 12: 993-998.

Meylan E, Dooley AL, Feldser DM, Shen L, Turk E, Ouyang C, Jacks T. 2009. Requirement for NF- $\kappa \mathrm{B}$ signalling in a mouse model of lung adenocarcinoma. Nature 462: 104-107.

Murray-Zmijewski F, Slee EA, Lu X. 2008. A complex barcode underlies the heterogeneous response of p53 to stress. Nat Rev Mol Cell Biol 9: 702-712.

Olive V, Bennett MJ, Walker JC, Ma C, Jiang I, Cordon-Cardo C, Li QJ, Lowe SW, Hannon GJ, He L. 2009. miR-19 is a key oncogenic component of mir-17-92. Genes Dev 23: 2839-2849.

Philippe L, Alsaleh G, Suffert G, Meyer A, Georgel P, Sibilia J, Wachsmann D, Pfeffer S. 2012. TLR2 expression is regulated by
microRNA miR-19 in rheumatoid fibroblast-like synoviocytes. $J$ Immunol 188: 454-461.

Smith ML, Ford JM, Hollander MC, Bortnick RA, Amundson SA, Seo YR, Deng CX, Hanawalt PC, Fornace AJ Jr. 2000. p53-mediated DNA repair responses to UV radiation: studies of mouse cells lacking p53, p21, and/or gadd45 genes. Mol Cell Biol 20: 3705-3714.

Tasdemir E, Maiuri MC, Galluzzi L, Vitale I, Djavaheri-Mergny M, D'Amelio M, Criollo A, Morselli E, Zhu C, Harper F, et al. 2008. Regulation of autophagy by cytoplasmic p53. Nat Cell Biol 10: 676-687.

Thomas A, Giesler T, White E. 2000. p53 mediates Bcl-2 phosphorylation and apoptosis via activation of the Cdc42/JNK1 pathway. Oncogene 19: 5259-5269.

Vopalensky V, Masek T, Horvath O, Vicenova B, Mokrejs M, Pospisek M. 2008. Firefly luciferase gene contains a cryptic promoter. RNA 14: 1720-1729.

Xu XM, Wang XB, Chen MM, Liu T, Li YX, Jia WH, Liu M, Li X, Tang H. 2012. MicroRNA-19a and -19b regulate cervical carcinoma cell proliferation and invasion by targeting CUL5. Cancer Lett 322: $148-158$.

Yan HL, Xue G, Mei Q, Wang YZ, Ding FX, Liu MF, Lu MH, Tang Y, Yu HY, Sun SH. 2009. Repression of the $m i R-17-92$ cluster by $\mathrm{p} 53$ has an important function in hypoxia-induced apoptosis. EMBO J 28: 2719-2732. 

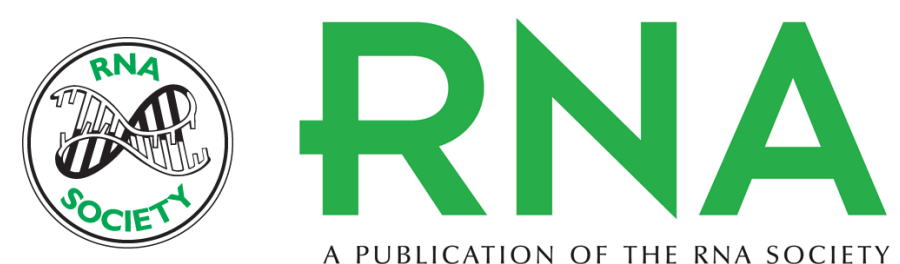

A PUBLICATION OF THE RNA SOCIETY

\section{miR-19b promotes tumor growth and metastasis via targeting TP53}

Yu Fan, Shenyi Yin, Yang Hao, et al.

RNA 2014 20: 765-772 originally published online April 17, 2014

Access the most recent version at doi:10.1261/rna.043026.113

Supplemental Material

References

Creative Commons License

Email Alerting Service
http://rnajournal.cshlp.org/content/suppl/2014/03/31/rna.043026.113.DC1

This article cites 25 articles, 10 of which can be accessed free at: http://rnajournal.cshlp.org/content/20/6/765.full.html\#ref-list-1

This article is distributed exclusively by the RNA Society for the first 12 months after the full-issue publication date (see http://rnajournal.cshlp.org/site/misc/terms.xhtml). After 12 months, it is available under a Creative Commons License (Attribution-NonCommercial 4.0 International), as described at http://creativecommons.org/licenses/by-nc/4.0/.

Receive free email alerts when new articles cite this article - sign up in the box at the top right corner of the article or click here.

To subscribe to $R N A$ go to:

http://rnajournal.cshlp.org/subscriptions 